\title{
Analysis on the Value of Network Media in Martial Arts Communication
}

\author{
Zhaohong Peng \\ Department of Sports, Sichuan University of Arts and Science, Dazhou 635000, Chinia \\ xxzengphysics@163.com
}

Keywords: Network media; TV media; Martial arts communication; Chinese martial arts

\begin{abstract}
Objective: In the internet era, we aim to study how to promote network media to all over the world based on network media so as to let more people study and be familiar with this national culture. Methods: We are going to adopt a combination method with documentary study and deductive proof and inductive analysis to carry out this research. Result: Chinese art can be spread based on various network media, including official Martial Arts website, Martial Arts forum, wechat and sina etc. Based on this, can we output culture and help people better understand martial arts. Conclusion: Network media is a new information dissemination tool, which can convey information faster to make people at all levels know the charm of martial arts and is not limited to time and regions. Based on television and network, we shape the image of Kung Fu Superstars, including Bruce Lee and Jackie Chen, which is beneficial to let more and more people have a general idea of martial arts and promote it to the world.
\end{abstract}

\section{Introduction}

Chinese martial arts, or in another word Chinese Kung Fu emerged based on Chinese traditional culture and aim to protect the country from enemies, which can be deemed as one of the survival skills in ancient times. Afterwards, people who are engaged in martial arts found out that it can help to strengthen the body and understand the relation between human beings and nature. As a result, soaring people begin to practice martial arts and understand the rules in compliance with objective laws as well as the charm of Chinese traditional culture. People who are engaged in martial arts are not boorish fellows, and prevention is one of the functions of it and a deeper connotation is the Chinese philosophy. The emergence of network era changed the original consumption, living and work mode of people, which brought new opportunities to a glittering array of traditional industries. The network communication is not limited to time and space, which can convey information much faster with multiple forms. So, this paper is going to study what effect Chinese martial art will have via network media and what value will it create.

\section{The Significance and Importance of the Combination between Network Media and Chinese Martial Art}

\section{Why Network Media?}

Before the new millennium, three media includes newspaper, television and broadcast. However, along with the approaching of information technology era, the idea of the fourth media came to the view of the public. Network media is different from the previous three media, which is a communication channel with words, photos, video and audio[1]. The information communication based on network is not limited to region, time and people, which is beyond certain limits and greatly improved the speed and range. Everyone can be the information provider in the premise of network technology and both individual and enterprise can be called we media to take advantage of intelligence and resources. Based on this, we are able to maximize the effect of promotion based on decreasing the cost. Comparing to traditional media, network media is faster and economical in price[2]. 


\section{The Inheritance of Martial Art Cannot be Separated from Network Media}

Chinese martial arts collect the essence of national culture and its communication has a positive to the inheritance of Chinese culture. In order to inherit the spirit and spread the culture of China, martial arts should go global. The development of international martial arts with Chinese characteristics will be an inevitable trend, which is obvious now. Therefore, in the opening ceremony and closing session of Beijing Olympic Games in 2008, we saw lots of people performing Chinese martial arts and those programs with power and features will not only bring about an audio-visual banquet but also create a profound effect on the Chinese culture. This is only one example and a very successful example of adopting network media[2].

In the context of network era, network media has become the fastest information communication method currently. In addition, the number of people using network is also soaring and the network popularization rate until June 2015 has achieved 48.8\%, which has been shown in table 1. What's more, the network technology is also improving a lot so to promote Chinese martial arts via network media is a trend. To accurately adopt network to convey information will let more and more people understand Chinese traditional cultures.

Table 1 The scale of Chinese netizens and network popularization rate Unit: thousand people

\begin{tabular}{|c|c|c|c|c|c|c|c|c|c|}
\hline & 2011.6 & $\begin{array}{l}2011.1 \\
2\end{array}$ & 2012.6 & $\begin{array}{l}2012.1 \\
2\end{array}$ & 2013.6 & $\begin{array}{l}2013.1 \\
2\end{array}$ & 2014.6 & $\begin{array}{l}2014.1 \\
2\end{array}$ & 2015.6 \\
\hline $\begin{array}{l}\text { Number } \\
\text { of } \\
\text { netizens }\end{array}$ & 48500 & 51310 & 53760 & 56400 & 59056 & 34758 & 63200 & 64875 & 66769 \\
\hline $\begin{array}{l}\text { Network } \\
\text { populariz } \\
\text { ation rate }\end{array}$ & $\begin{array}{l}36.20 \\
\%\end{array}$ & $\begin{array}{l}38.30 \\
\%\end{array}$ & $\begin{array}{l}39.30 \\
\%\end{array}$ & $\begin{array}{l}42.10 \\
\%\end{array}$ & $\begin{array}{l}44.10 \\
\%\end{array}$ & $\begin{array}{l}45.80 \\
\%\end{array}$ & $\begin{array}{l}46.90 \\
\%\end{array}$ & $\begin{array}{l}47.90 \\
\%\end{array}$ & $\begin{array}{l}48.80 \\
\%\end{array}$ \\
\hline
\end{tabular}

\section{What Methods of Network Media can be Adopted To Promote Martial Arts}

\section{Convey Information based on Network Media \\ Establish Chinese Martial Arts Website [3-5]}

Website is considered as a communication tool with words, photos and video etc. and by establishing a website, we can provide correct guidance for those who expect to understand the martial art culture. In addition, we can set different columns to introduce the background, culture and development of martial arts to help people have a concrete and systematic understanding. At present, there are several websites promoting martial arts, among which china-kungfu.net is relatively authoritative, which introduces the martial arts information in details and update the latest information, philosophy etc. In order to help people better understand the idea of martial arts, this website also provides the download function. By the way, this website was established in May 1, 2006 and has been operated until now.

\section{Establish Interactive Martial Arts Forum}

Concerning domestic forum, Tianya and mop etc. will appear in our mind, which belong to BBS (Bulletin Board System). We can upload and download data and comment [6]. In addition, we can also carry out information exchange to solve problems. What's more, in order to satisfy different needs of different customers, we can add some interesting sections for users to choose based on their own interest so as to understand relevant information. Even though the promotion of BBS is doing downhill, this kind of interactive forum cannot be ignored. Martial art is not only about theoretical knowledge but also practice. The establishment of martial arts forum can collect people with same interests and they can talk about this together. 


\section{Official Wechat and Sina Weibo Account of Martial Arts[6]}

Along with the popularization of smart phones, the development of mobile portal is facilitated. Until June 2015, there are $88.9 \%$ people surf the website via phones (see table 2: Data source study on the development status of network). What's more, the information communication via official wechat as well as sina weibo are gradually accepted by people. These two platforms can help to publish information for free, which can also help people carry out a small range interaction. Furthermore, these information communication methods are not limited to time and space, which can be done only via smart phones. Moreover, relevant martial training centers can take advantage of this new network media to popularize martial arts and demonstrate the charm to the public.

Table 2 Smart phone netizen scale and its proportion Unit: thousand people

\begin{tabular}{llllllllll}
\hline \multicolumn{1}{c}{ Year } & 2011.6 & 2011.1 & 2012.6 & $\begin{array}{l}2012.1 \\
2\end{array}$ & 2013.6 & 2013.1 & 2014.6 & 2014.1 & 2015.6 \\
2 & & & 2 & \\
\hline $\begin{array}{l}\text { Smart } \\
\text { phone } \\
\text { netizen }\end{array}$ & 31768 & 35558 & 38825 & 41997 & 46376 & 50006 & 52705 & 55678 & 59357 \\
$\begin{array}{l}\text { scale } \\
\text { proporti } \\
\text { on }\end{array}$ & $\begin{array}{l}65.50 \\
\%\end{array}$ & $\begin{array}{l}69.30 \\
\%\end{array}$ & $\begin{array}{l}72.20 \\
\%\end{array}$ & $\begin{array}{l}74.50 \\
\%\end{array}$ & $\begin{array}{l}78.50 \\
\%\end{array}$ & $\begin{array}{l}81.00 \\
\%\end{array}$ & $\begin{array}{l}83.40 \\
\%\end{array}$ & $\begin{array}{l}85.80 \\
\%\end{array}$ & $\begin{array}{l}88.90 \\
\%\end{array}$ \\
\hline
\end{tabular}

\section{Increase Operation Rate of TV Shows}

\section{Rebroadcast Domestic and Foreign Martial Arts Event}

Chinese martial arts are competitive, and there are big scale martial art events abroad, including Chinese Wushu Sanda King Tournament, Kunlun Ultimate Fighting Championship, Shaolin kungfu wrold martial arts festival etc. By rebroadcasting these events, we can help more and more people know the charm of Chinese martial arts and understand its features of being stable, accurate and strong so as to attract more fans. The development of martial arts events in China only has a short history with shortages in terms of rebroadcast scale and form. Therefore, we have to refer to excellent foreign cases, including NBA rebroadcast so as to promote the martial arts via Television rebroadcast[7].

\section{Increase the Effect of Martial Superstars}

Concerning the history for Chinese martial arts to go global, lots of representatives have appeared, including Bruce Lee, Jackie Chen, Jet Li, Donnie Yen. They let people all over the world know the charm of martial arts based on their fascinating performance in Kungfu movies. Bruce Lee, as a world martial arts idol, combines the martial arts with Chinese characteristics together with western martial art and western people have a deep impression on him. At the same time, people of other countries begin to have an interest on Chinese martial arts[4]. This is a pivotal step for Chinese martial arts to go global and the effect created by those martial arts superstars are far more than these. Their existence can be considered as a logo, and the culture output will be easier to be accepted based on them.

\section{Establish Brand and Stimulate National Patriotic Emotion}

There are lots of organizations known for Kickboxing internationally, including WBC, WMC, UFC, WKA, K-1 etc, these organizations help to cultivate high-quality talents. They will demonstrate people the beauty of strength on events. In addition, Chinese martial art is going global, in the meanwhile more and more martial people begin to be interested in kickboxing. Martial arts with national features can also make people feel the essence of Chinese culture based on kickboxing. Culture is the base for national development and when people see that the martial art going global, they will feel proud of their country. So, they will try the utmost to promote it. 


\section{The Current Promotion Condition of Martial Arts Via Network Media}

\section{The Condition of Network Media}

Sports events can be considered as the most direct approach for martial art communication. In addition, lots of events are broadcast live, no matter individual broadcast or regular video websites. When the network services as the media, we can make information communication faster. Besides video broadcast, we can also see the soaring number of searching martial arts, Chinese Kung Fu etc. We can know that people from all over the word are trying to get access to it via network and with different forms.

\section{TV Programs Rebroadcast}

Television rebroadcast is an important means for martial arts communication and Star TV in China will do rebroadcast based on different forms, including independent shows and sporty events communication, which all clear the pivotal role of martial arts communication. CCTV has Martial Arts program, Hunan Satellite TV has a competitive martial art program called Wulinfeng, CCTV will rebroadcast Wushu Sanda King Tournament and Fujian Satellite has a martial art column. In 2008, the rebroadcast of Beijing Olympic Games reached the peak and people can feel the charm of Chinese martial arts via TV.

\section{Several Suggestions to Adopt Network Work Media}

\section{Systematic Management for Martial Arts Website}

However, the martial art websites are promiscuous and when people search, lots of information will come to people's eyes and they will not have a systematic idea. In order to regulate the information, we have to systematically plan and sort the website based on functions, fully enrich the content, optimize the guide and provide downloading function. Moreover, in order to expand the effect, the website should support multiple languages and people can comment freely with interactions. Furthermore, websites should add two-way link to increase flow.

\section{Focus on the Updating Frequency of Network Media Information[4]}

No matter martial arts website, forum, wechat or Sina Weibo, we have to frequently update information especially forum and Weibo because they have relatively interactive, which need more practical information. It is better when the news being updated quickly and it can bring about more flows. Official wechat accounts have a certain updating frequency, and we can update hot topics and fresh news to make people think after reading, please see table 3.

Table 3 Chinese website quantity Unit/ thousand

\begin{tabular}{llllllllll}
\hline Year & 2011.6 & 2011.1 & 2012.6 & 2012.1 & 2013.6 & 2013.1 & 2014.6 & 2014.1 & 2015.6 \\
& & 2 & & 2 & & 2 & & 2 & \\
\hline $\begin{array}{l}\text { Quanti } \\
\text { ty }\end{array}$ & 183 & 230 & 250 & 268 & 294 & 320 & 273 & 335 & 357 \\
\hline
\end{tabular}

\section{Highlight the Details of TV Rebroadcast}

The rebroadcast of various sporty events needs the cameraman to do Lens analysis, so people have a better knowledge of martial arts will be handy. Based on Lens report, can we help people understand the philosophy of martial arts.

\section{Conclusion}

The development of Chinese martial arts, to some extent, promotes the development of Chinese nation, so how to carry out good communication is a thing worth pondering. Whether establishing martial arts websites, interactive forum, wechat, Weibo, or rebroadcast, we have to carry out a systematic information management. Only in this way, can we enhance the glory and promote in a 
meticulous and comprehensive way so as to carry forward Chinese martial art and inherit Chinese culture.

\section{References}

[1] S. Reed, American sports writers' social media use and its influence on professionalism, Journalism Practice, 2013, 7(5):555-571

[2] B Zheng, W Wang, G Jiang, K Wang, X Mei, Research status and application prospects of manufacturing technology for micro-nano surface structures with low reflectivity, Proceedings of the Institution of Mechanical Engineers, 2014, 229(11): 953-965

[3] Anonymous. Youth Empowerment Through Sports Toward Health and Social Development Forum. Research Quarterly for Exercise and Sport,2016, 87S2:.

[4] N O'Reilly, IE Berger, T Hernandez, MM Parent, B Seguin , Understanding adolescent sport participation through online social media[J]. Sport, Business and Management, 2012, 2(1):69-81

[5] MR Green, The impact of social networks in the development of a personal sports brand. Sport, Business and Management, 2016,6, 274-294

[6] S Vallor, Flourishing on facebook: virtue friendship \& new social media, Ethics and Information Technology, 2012, 14(3):1-15

[7] Deubel, P., An investigation of behaviorist and cognitive approaches to instructional design. Journal of Educational Multimedia and Hypermedia, 12(1), 63-90.2003.

[8] Christanse, R., Effects of technology integration education on the attitudes of teachers and students. Journal of Research on Technology in Education, 34(4) 411-434, 2002.

[9] Collier, K. G., Paula, F.J. \& Goff, R.J., Colleges of Education Learning Programmes: A proposal (Working Paper No.5). Washington, DC: Commission on Instructional Technology, 1971.

[10]Crowther, M. S., Keller, C. C. \& Waddoups, G. L., Improving the quality and effectiveness of computer-mediated instruction through usability evaluations. British Journal of Educational Technology, 35(3), 289-303, 2004.

[11]Dincer B., Özaslan, M. ve Kavasoğlu., T., İllerin ve bölgelerin sosyo ekonomik gelişmişlik sıralaması araştırması. Ankara: Devlet Planlama Teskilatı Yay., 2671, 2003. 